\title{
Correction to: \\ MicroRNA-193 Pro-Proliferation Effects for Bone Mesenchymal Stem Cells After Low-Level Laser Irradiation Treatment Through Inhibitor of Growth Family, Member by Wang J, et al. Stem Cells Dev 2011;21;13;2508-2519 DOI:10.1089/scd.2011.0695
}

7 He authors of the article entitled MicroRNA-193 Pro-Proliferation Effects for Bone Mesenchymal Stem Cells After Low-Level Laser Irradiation Treatment Through Inhibitor of Growth Family, Member published in Stem Cells Dev 2011;25;21:2508-2519 wish to correct an error.

In Figure 5B, the figures for flow cytometric assay of anti-miR-193 and anti-miR-133b were identical. This was incorrect. Here, we provide the original data file of flow cytometric assay as well as the corrected figure.

The original Figure 5B is below:

The revised Figure 5B is shown below.

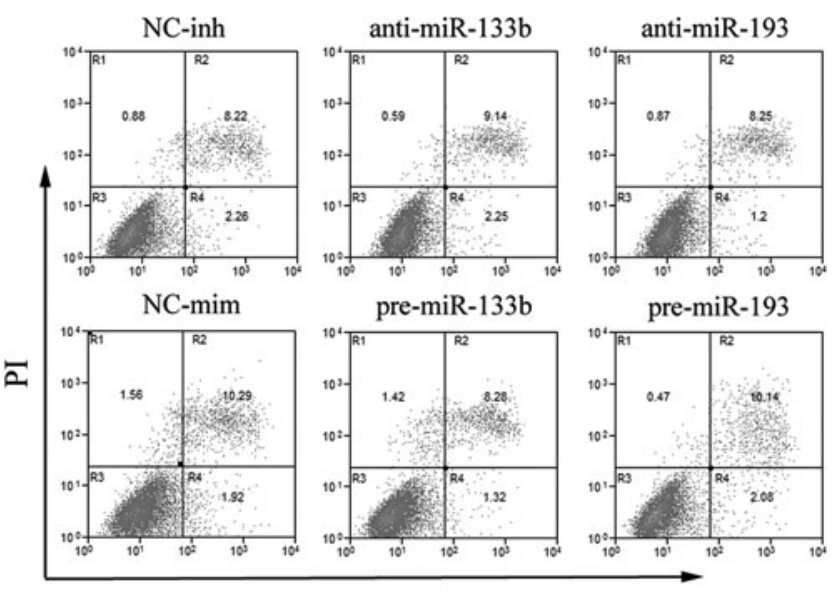

AnnexinV-FITC
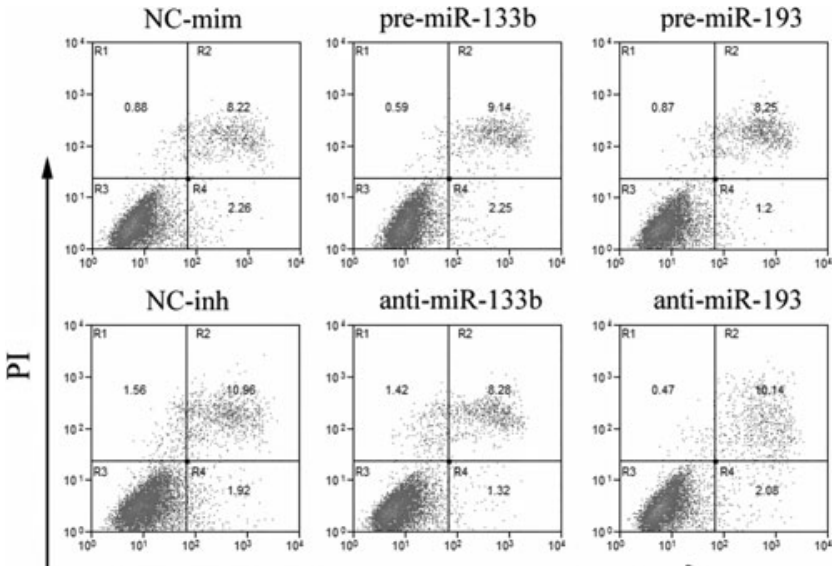

anti-miR-133b

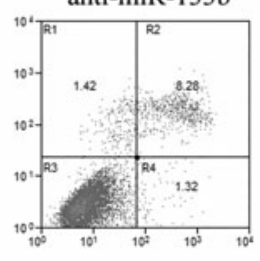

anti-miR-193

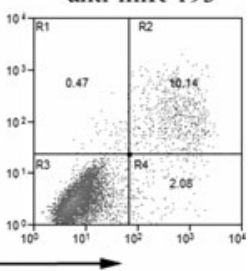

AnnexinV-FITC

The online version of this article has been revised to reflect this correction.

The authors sincerely regret this error. 